\title{
Reactive attachment disorder and disinhibited social engagement disorder in adolescence: co-occurring psychopathology and psychosocial problems
}

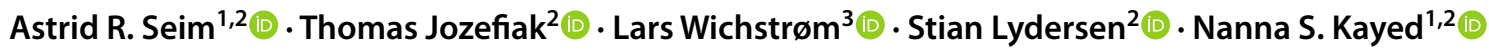

Received: 1 April 2020 / Accepted: 23 October 2020 / Published online: 13 November 2020

(c) The Author(s) 2020

\begin{abstract}
Insufficient care is associated with most psychiatric disorders and psychosocial problems, and is part of the etiology of reactive attachment disorder (RAD) and disinhibited social engagement disorder (DSED). To minimize the risk of misdiagnosis, and aid treatment and care, clinicians need to know to which degree RAD and DSED co-occur with other psychopathology and psychosocial problems, a topic little researched in adolescence. In a national study of all adolescents $(N=381 ; 67 \%$ consent; 12-20 years old; 58\% girls) in Norwegian residential youth care, the Child and Adolescent Psychiatric Assessment interview yielded information about psychiatric diagnoses and psychosocial problems categorized as present/absent, and the Child Behavior Check List questionnaire was applied for dimensional measures of psychopathology. Most adolescents with a RAD or DSED diagnosis had several cooccurring psychiatric disorders and psychosocial problems. Prevalence rates of both emotional and behavioral disorders were high in adolescent RAD and DSED, as were rates of suicidality, self-harm, victimization from bullying, contact with police, risky sexual behavior and alcohol or drug misuse. Although categorical measures of co-occurring disorders and psychosocial problems revealed few and weak associations with RAD and DSED, dimensional measures uncovered associations between both emotional and behavioral problems and RAD/DSED symptom loads, as well as DSED diagnosis. Given the high degree of comorbidity, adolescents with RAD or DSED—or symptoms thereof-should be assessed for co-occurring psychopathology and related psychosocial problems. Treatment plans should be adjusted accordingly.
\end{abstract}

Keywords Adolescence $\cdot$ Child welfare $\cdot$ Comorbidity $\cdot$ Disinhibited social engagement disorder $\cdot$ Mental health . Psychosocial problems $\cdot$ Reactive attachment disorder

Electronic supplementary material The online version of this article (https://doi.org/10.1007/s00787-020-01673-7) contains supplementary material, which is available to authorized users.

Astrid R. Seim

astrid.r.seim@ntnu.no

1 Department of Child and Adolescent Psychiatry, St. Olavs Hospital, Trondheim, Norway

2 Department of Mental Health, Faculty of Medicine and Health Sciences, NTNU Norwegian University of Science and Technology, Trondheim, Norway

3 Department of Psychology, NTNU, Trondheim, Norway

\section{Introduction}

Childhood maltreatment and neglect are associated with a wide range of psychiatric disorders and psychosocial problems [1-3] and may, in severe cases, cause reactive attachment disorder (RAD) and disinhibited social engagement disorder (DSED) [4]. Distinguishing between various health effects of childhood adversity may be clinically challenging, and there is a particular risk and tendency to misdiagnose RAD and DSED [5, 6], either by the under-identification of common psychiatric disorders and neurodevelopmental problems and the over-identification of attachment problems [5, 7-9] or vice versa $[10,11]$. Misdiagnosis may result in missed treatment and developmental support, prolonging individual suffering, functional impairment, and societal costs. To improve diagnostic precision and aid the development of appropriate treatment plans, health and social 
workers need to be knowledgeable about the degree of cooccurrence between RAD or DSED and other psychopathology and psychosocial problems. However, at present, we know comparatively little about this co-occurrence in adolescence. Although several studies have investigated the associations between RAD and DSED and other psychopathology in preschool and school-aged children, existing results are inconsistent and may be prone to type-II error due to categorical approaches and small sample sizes $[12,13]$. Moreover, because of heterotypic continuity and differences in rates of psychopathology between childhood and adolescence $[2,14,15]$, findings in younger children cannot necessarily be ascribed to adolescents. The psychiatric comorbidities of RAD and DSED may also differ in different contexts, and remain largely unexplored among adolescents exposed to in-family maltreatment and neglect where placement in well-functioning foster or adoptive families has failed, thus culminating in institutional care. Furthermore, additional psychosocial problems known to be associated with maltreatment and neglect, including suicidality, self-harm, alcohol or drug misuse, victimization from bullying, risky sexual behavior and criminal behavior [1, 3], may influence care and treatment for children with RAD or DSED. At present, we do not know the extent to which such problems are present in RAD and DSED. Therefore, to help clinicians and services attend to the complex clinical picture often presented in individuals exposed to early adversity, while having access to a national high-risk sample, we investigate the rates of co-occurrence and strengths of associations between RAD and DSED and other psychiatric disorders and emotional, behavioral and psychosocial problems among adolescents living in residential youth care (RYC).

RAD is characterized by social withdrawal and aberrant attachment behavior with failure to seek and respond to comfort, whereas DSED is characterized by socially disinhibited behavior and the lack of reticence in unfamiliar settings or interactions with strangers [4]. Both RAD and DSED have been demonstrated as valid diagnostic constructs, distinct from other psychopathology in childhood and adolescence [16-22], and symptoms may persist into adolescence and early adulthood, with potentially large individual and societal costs [2, 23-26]. Because the fourth edition of the Diagnostic and Statistical Manual of Mental Disorders (DSM-IV) defines the concepts corresponding with RAD and DSED as two subtypes of one disorder [27], contrary to the two distinct disorders in the DSM-5 [4], previous research often investigated RAD and DSED as a combined diagnostic concept. A combined RAD and DSED is reported to frequently co-occur with both emotional symptoms and disorders (such as depression and anxiety) and behavioral symptoms and disorders (such as oppositional defiant disorder (ODD), conduct disorder (CD) or attention deficit hyperactive disorder (ADHD)) [28-37]. When distinguishing between RAD and
DSED, scientists have expected RAD (or the 'RAD inhibited type' in studies using the DSM-IV), with its socially withdrawn phenotype, to be associated with emotional problems and DSED (or the 'RAD disinhibited type' in studies using the DSM-IV), with its indiscriminate phenotype, to be associated with behavioral problems [22].

Some studies on RAD have confirmed these expectations in preschool and school-aged children [13, 38, 39]. Others have found that symptoms of RAD in preschoolers have no correlations with any psychopathology [36], or found ambiguous associations depending on the sample [40]. Contrary are findings that RAD symptoms or disorder in school-age and early adolescence may be associated with both emotional and behavioral problems [26, 41-43]. Beyond age 12, the comorbidity for RAD remains unstudied.

Similarly, for DSED in preschool and school-aged children, some studies have confirmed the above expectations, either by investigating associations with behavioral and not emotional problems $[11,19]$ or by investigating both and finding associations only with behavioral problems [41, $44,45]$. Conversely, others have found that DSED in preschool and school-age children may co-occur [31, 38, 42] or be positively associated $[36,39,46]$ with both emotional and behavioral disorders or problems. Beyond school age, persistent DSED symptoms in young adults adopted from early institutional deprivation to well-functioning families in preschool age have been found to be associated with symptoms of ADHD and callous-unemotional traits (CU), though unrelated to depression, anxiety and CD symptoms [47]. Of note, generalizability to populations unexposed to early severe deprivation in institutions has been questioned [2, 48]. Early institutionalization is no longer a common practice in industrialized countries [46]. However, exposure to in-family maltreatment and neglect remains a major public health concern $[1,49]$. In non-institutionalized adolescents exposed to in-family maltreatment, DSED symptoms have been found to be associated with both emotional and behavioral problems [46], but prevalence rates of co-occurring psychiatric disorders and psychosocial problems remain undescribed.

To allow for advantages regarding both categorical and dimensional approaches to psychopathology [50], we use four approaches to illuminate the co-occurrence between RAD and DSED and other psychopathology and psychosocial problems. First, we investigate the degree to which other psychiatric disorders and categorical psychosocial problems (categorized as present or absent) co-occur with RAD and DSED diagnoses. This approach may be of clinical value, as diagnoses are clinical tools comprising more than mere cutoff values of symptom loads (i.e., taking into account onset, duration, distress, impairment and exclusion criteria). Second, we investigate whether the risks of having co-occurring psychiatric disorders and categorical psychosocial problems 
change with increasing RAD or DSED symptom loads. This approach affords higher statistical power than treating RAD and DSED as dichotomous variables and allows the inclusion of cases with sub-threshold levels of RAD and DSED symptom loads, where the psychiatric burden and impairment may be high despite the unfulfillment of some diagnostic criteria [50]. Third, inversely, as individuals with RAD or DSED may also be debilitated by other sub-threshold psychopathology, we investigate the levels of dimensionally measured emotional and behavioral problems for adolescents with RAD and DSED diagnoses compared to those without. Finally, we apply a dimensional approach to all variables and investigate whether emotional and behavioral problems are associated with RAD or DSED symptom loads. This final approach further increases statistical power and allows the analysis of sub-threshold cases with respect to both cooccurring psychopathology and RAD/DSED. Because RAD and DSED are distinct disorders in adolescence [21, 24], they are investigated separately in each approach.

In sum, we aim to study the rates of co-occurrence and strengths of associations between RAD and DSED, respectively, and other psychopathology and psychosocial problems in adolescence. We do so by assessing high-risk adolescents living in Norwegian RYC using in-depth psychiatric interviews and investigate psychiatric disorders and psychosocial problems (categorized as present or absent) and their (1) prevalence and odds in adolescents with RAD and DSED diagnoses; (2) association with increasing RAD and DSED symptom loads. Further, using a dimensional approach to other psychopathology, we investigate (3) the levels of emotional and behavioral problems in adolescents with RAD and DSED diagnoses; (4) whether emotional and behavioral problems are associated with RAD and DSED symptom loads.

\section{Methods}

\section{Participants}

The research project Mental Health in Adolescent Residents in the Child Welfare System [51] invited all residents aged 12-23 years living in Norwegian RYC between 2011 and 2014 to participate. Due to a presumed state of high crisis, adolescents in acute placements and unaccompanied minors without Norwegian asylum were excluded, as were adolescents without sufficient Norwegian language proficiency to complete the psychiatric interviews. In total, 400 of $601(67 \%)$ eligible adolescents in 86 RYC institutions consented, with $N=381$ yielding information about RAD and DSED. The recruitment flowchart is shown in Figure S1 (Online Resource). The participants were between 12.2 and 20.2 years old $(M=16.7$, SD 1.4$), 57.7 \%$ were girls $(n=220)$, and $78.2 \%$ were ethnic Norwegian. The mean age at the first out-of-home placement was 12.5 years (SD 3.9), and the mean number of out-of-home placements was 3.3 (SD 2.4). In total, $n=8$ participants had previously been diagnosed with mild intellectual disability, whereof $n=1$ qualified for RAD and $n=2$ for DSED. Previous studies of the same participants revealed very high rates of psychiatric morbidity and high levels of parental risk factors, such as drug use or mental or chronic illness [51]. Virtually, all the participants were likely exposed to in-family neglect, and $71 \%$ self-reported exposure to maltreatment [52]. We have previously reported the symptom frequency range for RAD and DSED as $2-35$ and $4-11 \%$, respectively, and the diagnose prevalence rates as 9\% RAD $(n=33)$ and $8 \%$ DSED $(n=31)$, with $0.5 \%(n=2)$ having both disorders [21].

\section{Setting}

The primary aim of the Norwegian child protection services (CPS) is to provide in-family support to children and families in need and invoke out-of-home placements only when considered necessary to secure provision of a child's basic needs [53]. In such cases, foster care is preferred, and RYC represents a last resort [54]. In accordance with the CPS criteria for out-of-home placements [55], adolescents living in Norwegian RYC have likely been exposed to social neglect, inadequate care or maltreatment prior to placement. Although placements due to behavioral problems or drug use are more frequent for adolescents in RYC than in foster care, traits of the caregiving environment (e.g., parental mental illness or drug use, lack of caregiving ability or other factors in the home) are the most common reasons for placement, regardless of placement type [54].

Norwegian RYC institutions typically resemble family homes with three-eight residents and are strictly regulated by law and quality requirements to ensure that all residents are provided with basic needs and a secure, developmentally supportive environment [56]. There is awareness of the importance of relational continuity. Every resident has a designated primary contact whose aims are to establish a trusting relationship and fulfill the role of a primary caretaker for their designated resident. Given these circumstances, and the fact that $90 \%$ of the participants reported to have lived at least three months in RYC prior to the data collection [57], the primary contacts were trusted as reliable informants. Further details on the setting are given in $[21,51]$.

\section{Procedure}

The data were collected at RYC institutions from June 2011 to July 2014. Four trained research assistants with relevant professional backgrounds completed semi-structured psychiatric interviews with the participants and their primary 
contacts. The study was approved by the Norwegian Regional Committee for Medical and Health Research Ethics, REC central Norway, and all participants gave written informed consent.

\section{Measures}

\section{Interview with adolescents}

The Child and Adolescent Psychiatric Assessment (CAPA) [58] is an in-depth semi-structured psychiatric interview which determines psychiatric disorders in children and adolescents, as defined by DSM-IV. The CAPA collects information about symptom onset, duration, frequency and intensity and includes both required and optional followup questions. Interviewers probe until they clarify the presence of predefined symptom criteria. The following psychiatric disorder categories and psychosocial problems were assessed using CAPA: depression, anxiety, CD/ODD, suicidal thoughts, suicidal plan, suicidal attempt, suicidal behavior without suicidal intent, self-injurious behavior without suicidal intent (self-harm), exposure to bullying, contact with police, sex for gain, substance use (daily use of alcohol or ever having used cannabis or hard drugs) and substance use for mood improvement. A three-month primary period was applied to all the CAPA variables, except for the following, where a lifetime period was applied: suicidal attempt, been bullied often, contact with police, sex for gain and substance use.

\section{Interview with the adolescents' primary contacts}

Adolescents are considered to be less reliable informants regarding symptoms of ADHD than adults who know them well [59]. Further, because self-acknowledging signs of RAD and DSED would require mentalization abilities beyond what could be expected of adolescents with RAD and DSED, due to the lack of supportive caregiving relationships necessary to promote mentalization [60], adolescents were expected to be sub-optimal informants of RAD and DSED symptoms. Therefore, ADHD, RAD and DSED were assessed using the adolescents' primary contacts as informers. ADHD was assessed using the caregiver version of CAPA and RAD/DSED using the RAD module in the Preschool Age Psychiatric Assessment (PAPA) [61]. The DSM-5 criteria [4] were applied in diagnosing RAD and DSED; however, we lacked the RAD item 'response to comfort'.

To prevent interviewer drift and ensure adherence to the interview protocol, the interviews underwent regular and random controls. To provide inter-rater reliability estimates, blinded raters re-coded a randomly drawn sample $(n=42$; $10.5 \%)$ of interview audio recordings. Inter-rater reliability for the DSM-IV by Gwet's $\mathrm{AC}_{1}$ was in the range of $0.74-1.0$, and the absolute agreement was in the range of $83-100 \%$ [51].

\section{Child Behavior Checklist (CBCL)}

To obtain information about sub-threshold emotional and behavioral problems, the adolescents' primary contacts completed the CBCL for ages 6-18 [62], a well-validated caregiver questionnaire with 118 items, yielding the following syndrome scales: anxiety/depressed, withdrawn/depressed, somatic complaints, social problems, thought problems, attention problems, rule-breaking behavior and aggressive behavior. The CBCL items classified as 'other problems' were also included.

\section{Statistical analysis}

Among the 381 subjects, 59 cases had information about RAD, DSED, ADHD, and CBCL syndrome scales, but had missing information about other CAPA-informed comorbid disorders and psychosocial problems because their primary contacts had completed the diagnostic interview, but the adolescents themselves had not. Missing data were handled by multiple imputation. In the imputation model, we used all variables to be included in the analysis. Imputation for girls and boys was done separately. We created 100 imputed data sets, generally regarded as sufficient [63]. We chose not to restrict the imputed values to the possible range, as recommended by Rodwell et al. [64]. Differences in means were analyzed using the Student's $t$ test. Associations between RAD or DSED and the continuous variables were investigated using linear regression and the dichotomous variables using logistic regression. All regression analyses were adjusted for age and gender. Neither age at first placement nor the number of out-of-home placements were in complete case analyses associated with RAD or DSED diagnosis or symptom loads, and were not included in the imputation model. Two-sided $p$ values $<.05$ were taken to indicate statistical significance, and 95\% confidence intervals (CI) are reported where relevant. Due to multiple hypotheses, $p$ values between .01 and .05 should be interpreted with caution. We used SPSS 25 for all analyses.

\section{Results}

\section{RAD}

Among adolescents with a RAD diagnosis, all disorders (Table 1, Fig. 1) were prevalent, and 65\% fulfilled the criteria for at least one additional psychiatric disorder, with 53\% fulfilling the criteria for at least two and $20 \%$ at least three. 


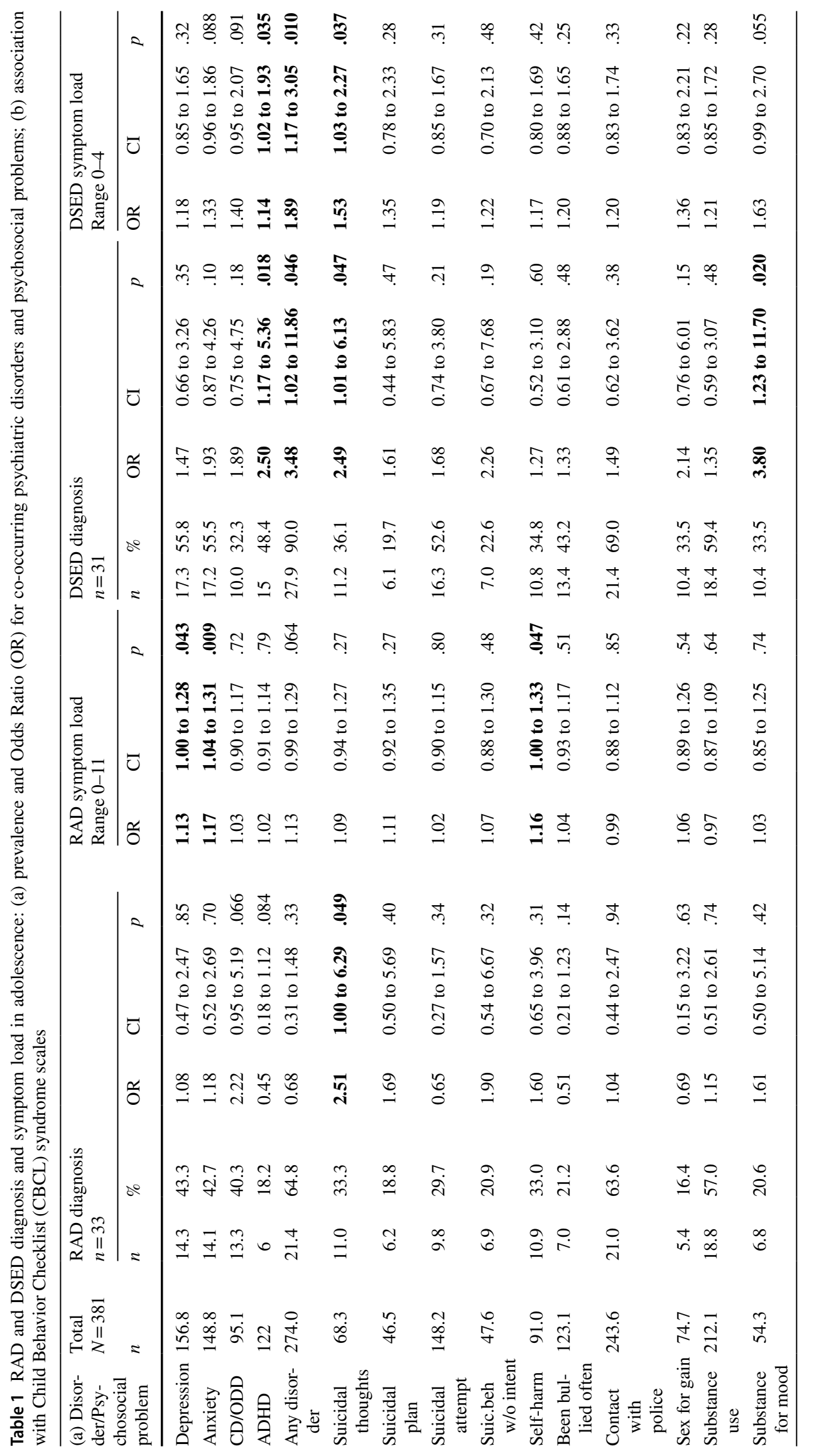




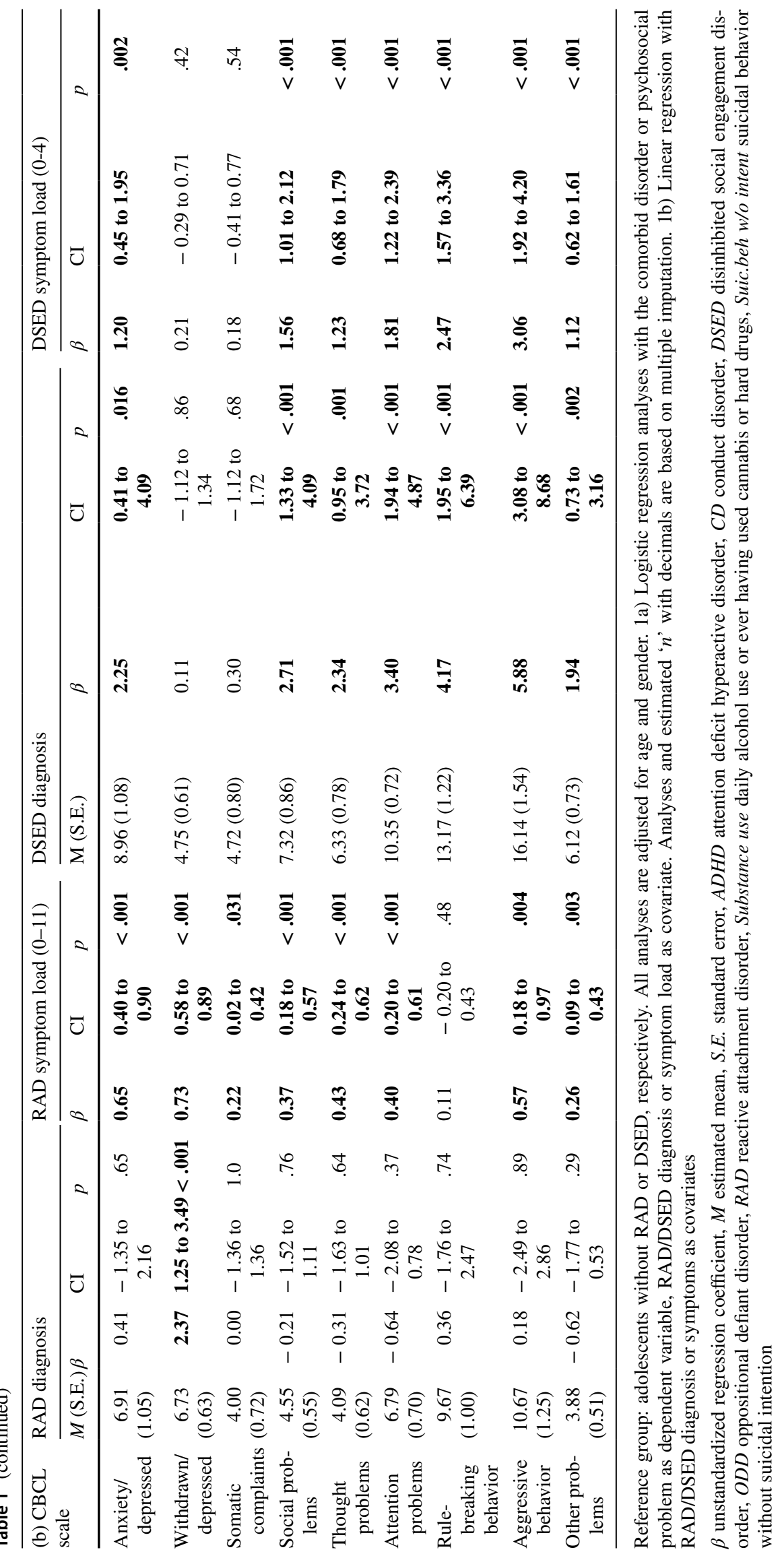




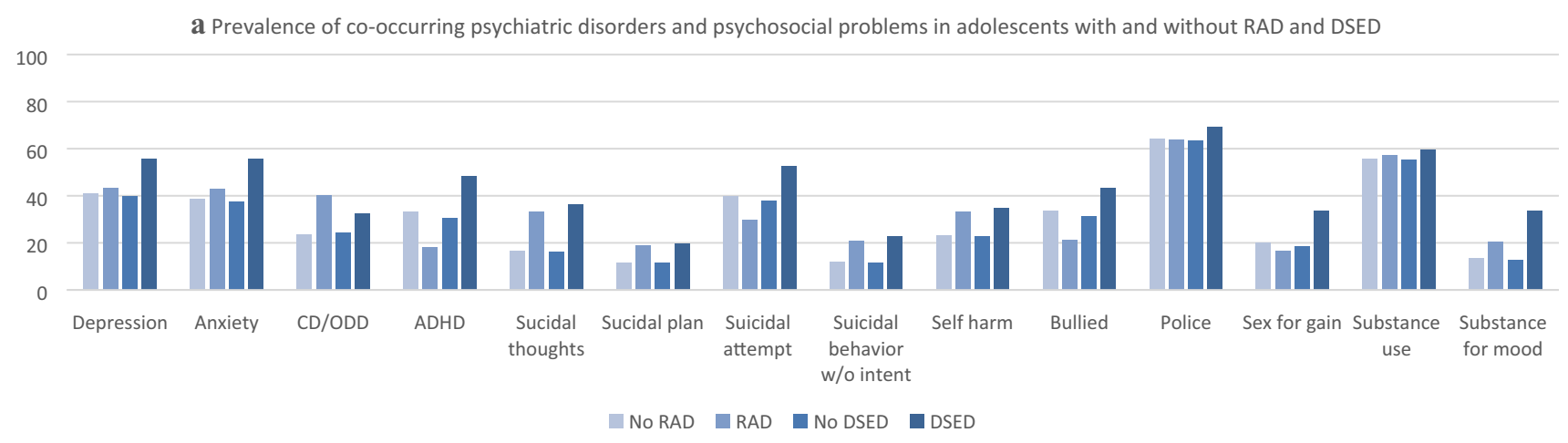

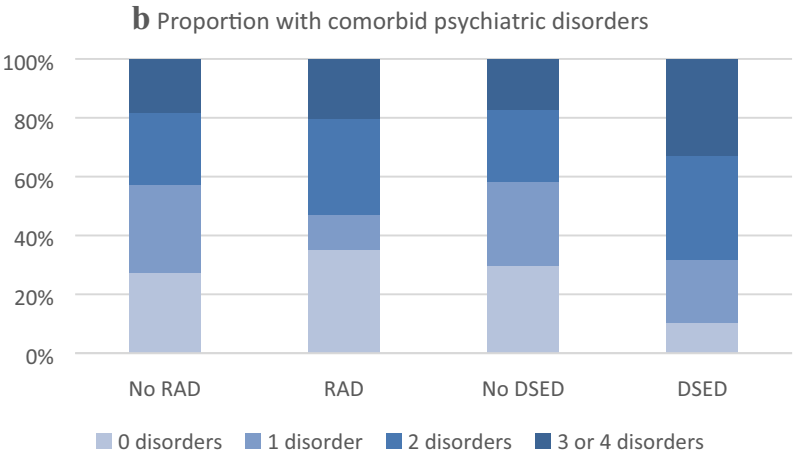

Fig. 1 Prevalence (\%) of co-occurring psychiatric disorders and psychosocial problems in adolescents with and without RAD and DSED diagnosis (a). Proportion (\%) of adolescents with and without a RAD

Further, all categorical psychosocial problems (Table 1, Fig. 1) were prevalent among adolescents with a RAD diagnosis, and $92 \%$ reported at least one co-occurring psychosocial problem, with $49 \%$ reporting at least three and $30 \%$ at least five. Nevertheless, this high-risk sample presented no differences in the rates of categorical psychiatric disorders or psychosocial problems for adolescents with a RAD diagnosis, compared to those without, except for suicidal thoughts, for which adolescents with a RAD diagnosis had 2.5 times increased odds (Table 1). Adolescents with a RAD diagnosis had means of 1.44 comorbid psychiatric disorders (range $0-4$, mean difference 0.08 (CI -0.35 to $0.51, p=.72$ ) higher than adolescents without RAD) and 3.15 co-occurring psychosocial problems (range $0-10$, mean difference 0.26 (CI -0.50 to $1.02, p=.51$ ) higher than adolescents without RAD). The odds of depression and anxiety increased with an increasing number of RAD symptoms, as did the odds of self-harm (Table 1). The remaining psychiatric disorders and categorical psychosocial problems were not associated with RAD symptom load in this high-risk sample. Through dimensional measures of other psychopathology, the sole clinically significant regression coefficient and statistically significant association for a RAD diagnosis was with the CBCL withdrawn/depressed syndrome scale (Table 1). However, the RAD symptom load had clinically

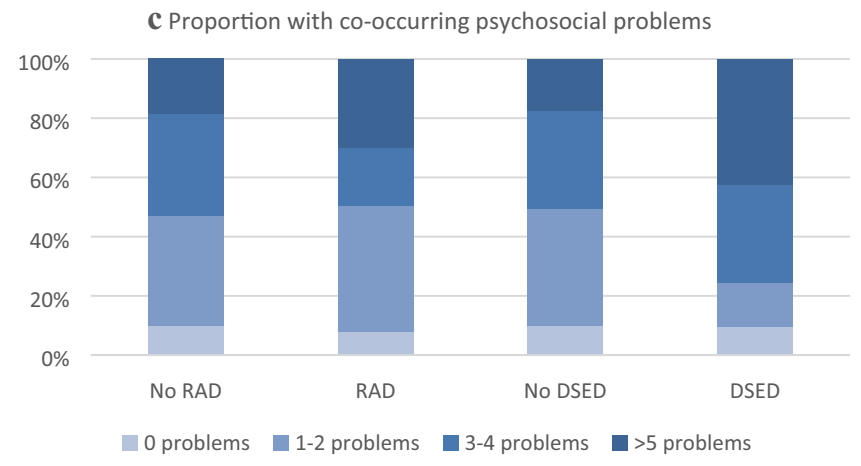

and DSED diagnosis who have co-occurring psychiatric disorders (b) and psychosocial problems (c)

significant regression coefficients and statistically significant associations with all the CBCL syndrome scales, except rule-breaking behavior (Table 1).

\section{DSED}

All disorders (Table 1, Fig. 1) were prevalent among adolescents with a DSED diagnosis, and $90 \%$ fulfilled the criteria for at least one additional psychiatric disorder, with $68 \%$ fulfilling the criteria for at least two and $33 \%$ at least three. The odds of ADHD were 2.5 times higher, and the odds of any other psychiatric disorder 3.5 times higher for adolescents with a DSED diagnosis than those without. Adolescents with a DSED diagnosis had a mean of 1.92 comorbid disorders (range $0-4$, mean difference 0.60 (CI 0.17 to $1.03, p=.006$ ) higher than adolescents without DSED). All categorical psychosocial problems were also prevalent among adolescents with a DSED diagnosis (Table 1, Fig. 1), and 91\% reported at least one co-occurring psychosocial problem, with $76 \%$ reporting at least three and $42 \%$ at least five. Adolescents with a DSED diagnosis had a mean of 4.04 co-occurring psychosocial problems (range 0-10, mean difference 1.23 (CI 0.34 to $2.11, p=.006$ ) higher than adolescents without DSED). The odds of suicidal thoughts and substance use for mood improvement were higher among adolescents with a 
DSED diagnosis compared to those without. Further, the odds of having ADHD, any comorbid disorder or suicidal thoughts increased with increasing DSED symptom load (Table 1). For the remaining categorical psychiatric disorders and psychosocial problems, we found no associations with DSED symptom load in this high-risk sample. However, by dimensional measures of other psychopathology, we found DSED diagnosis and symptom load to be associated with the following CBCL syndrome scales: anxiety/ depressed, social problems, thought problems, attention problems, rule-breaking behavior, aggressive behavior and other problems (Table 1). Scores on the CBCL syndrome scales withdrawn/depressed and somatic complaints were neither associated with DSED diagnosis nor symptom load.

\section{Discussion}

RAD and DSED are often misdiagnosed in children and adolescents with histories of neglect, either by overidentifying or overlooking the attachment-related nature of their problems or-when rightly recognized — not acknowledging comorbid conditions. To counteract this tendency toward misdiagnosis and elaborate on the complex clinical picture often presented in individuals exposed to early adversity, we investigated the co-occurrence of other psychopathology and psychosocial problems among adolescents with and without RAD and DSED in a national study of high-risk adolescents living in RYC. This is the first in-depth study of RAD and DSED comorbidity in adolescence to report prevalence rates of co-occurring psychiatric disorders and psychosocial problems, and to explore associations using both categorical and dimensional approaches to psychopathology. We found that most adolescents with RAD or DSED diagnoses had additional psychiatric disorders and psychosocial problems and that all investigated disorders and psychosocial problems of both emotional and behavioral types frequently co-occurred with both RAD and DSED. In general, analyses based on categorical variables have lower statistical power than those based on the corresponding scale variables. Indeed, in analyses of associations between RAD and DSED and other psychopathology in this high-risk sample, the choice of categorical measures versus dimensional measures was decisive for the results. The categorical measures in the analytical approaches to co-occurring psychopathology and psychosocial problems revealed few and not highly statistically significant differences between adolescents with and without RAD and DSED, whereas the dimensional measures clearly showed that RAD and DSED symptom loads and a DSED diagnosis were all associated with both emotional and behavioral problems.

Consonant with the lasting negative effects of childhood neglect and maltreatment $[1,65]$, the prevalence rates of both emotional and behavioral disorders [14, 66, 67] and frequencies of psychosocial problems [68-70] were markedly higher among adolescents with RAD or DSED than in the general population and were comparable to findings in other adolescents subjected to child abuse and neglect [71]. The prevalence rates were as high or higher than in early institutionalized preschool and 12-year-old children assigned to 'care as usual' in the Bucharest Early Intervention Project (BEIP) [72, 73]. Possibly, individuals with RAD/DSED and co-occurring psychopathology or psychosocial problems have increased risk of repeated placement breakdown with subsequent placement in RYC, introducing elevated comorbidity rates in this study. On the other hand, longitudinal findings in the BEIP revealed that placement disruptions predicted psychopathology, rather than vice versa [72], which may also apply to adolescents in RYC. Indeed, the participants in our study had multiple placement disruptions and high ages at first placement, both key risk factors of emotional and behavioral problems in looked-after children [74]. Further, developmental changes from childhood to adolescence, i.e., higher prevalence rates of emotional, behavioral and substance use disorders in adolescence [14, 67], may contribute to the higher psychiatric morbidity in this study compared to studies of younger children. In any case, the findings demonstrate high levels of comorbidity and additional psychosocial burdens for adolescents with RAD and DSED in RYC settings. Of note, even though most adolescents with RAD or DSED qualified for at least one additional psychiatric disorder, no single diagnostic category was present in more than half of those with RAD or DSED, and only a minority of adolescents with the other disorders had comorbid RAD or DSED, supporting previous findings of the discriminant validity of RAD and DSED in adolescence [21].

\section{RAD}

Finding that both emotional and behavioral problems may co-occur with RAD and be associated with RAD symptom load in adolescence is concordant with previous findings among school-aged children and early adolescents [26, 41-43]. However, this result contradicts that of studies among pre-schoolers, which report that RAD is associated with more emotional problems and not with more behavioral problems [39, 40,75]. Although there is a possibility of type-II errors where observed differences are not statistically significant due to small sample sizes, the above studies of pre-schoolers used dimensional measures of psychopathology, thereby eliminating potential type-II errors due to reduced power by categorical measures. Therefore, rather than having predominantly methodological explanations, the differences in the findings between the associations of RAD in pre-schoolers and adolescents may be due to real 
developmental changes from childhood to adolescence, and the added risk from many placement disruptions and high age at the first placement.

Although depression and anxiety were the most common comorbid disorders among adolescents with RAD, CD/ODD was nearly as common and present in $40 \%$ of those with a RAD diagnosis. This high comorbidity rate may shed light on the conceptual confusion pertaining to older children and adolescents, whose conduct problems may be misinterpreted as RAD [9, 76]. Importantly, our findings clearly demonstrate that while many with RAD had co-occurring CD/ODD, most adolescents with RAD did not. Moreover, despite the high-risk nature of the sample, only a small minority (14\%) of all adolescents with CD/ODD had a cooccurring RAD diagnosis. Further, although RAD symptom load was associated with the dimensional measure of aggressive behavior, illustrating that adolescents with RAD may have additional behavioral problems, neither the categorical measures of CD/ODD or contact with the police, nor the dimensional measure of rule-breaking behavior was associated with RAD. Therefore, although both conduct problems and RAD are associated with maltreatment and neglect and are malleable by caregiver behavior [39, 72], conduct problems in individuals with histories of maltreatment and neglect are not equivalent to RAD and should not be interpreted as such.

The lack of increased odds of most other forms of psychopathology with a RAD diagnosis, as opposed to not having RAD, must be understood in light of the high-risk nature of the sample, with a very high psychiatric morbidity also among the adolescents without RAD. Further, the reduced statistical power caused by dichotomizing RAD symptoms into a RAD diagnosis (present/absent) may partially explain a loss of statistical significance from the dimensional measure of RAD symptom load to the categorical RAD diagnosis. However, such a trend was not obvious where a categorical approach to co-occurring psychopathology and psychosocial problems was used. Indeed, we see the opposite tendency for the odds of co-occurring CD/ODD and ADHD, with lower $\mathrm{p}$-values for a RAD diagnosis than for RAD symptom load. Furthermore, although in the dimensional approach to other forms of psychopathology we see the expected loss of statistical significance by categorizing RAD symptoms into a RAD diagnosis, we note a lack of clinically significant regression coefficients for a RAD diagnosis (except for the association with CBCL 'withdrawn/depressed'), contrary to the RAD symptom load, illustrating that different approaches to RAD may reveal different results regardless of statistical power. One reason for this may be that the RAD diagnosis reflects more than a numerical cut-off level of RAD symptoms, as the diagnostic criteria require the presence of certain symptom clusters classified under A criteria (minimal comfort seeking/response) and B criteria (emotional dysregulation and limited emotional responsiveness) [4]. In a study of foster youth, self-reported potentially traumatic events were associated with B criteria, not with A criteria of DSM-5 RAD [77]. Possibly, the A and B criteria also differ in their associations with other psychopathology, potentially impacting our results.

Interestingly, in this high-risk sample, the sole association between a RAD diagnosis and dimensional measures of psychopathology was with the CBCL withdrawn/ depressed scale, mirroring findings among institutionalized pre-schoolers, where an observational measure of RAD was strongly related to the CBCL scales withdrawn/depressed and somatic complaints - though only weakly to a total score of emotional problems (internalizing score) - and were not associated with behavioral problems [75]. Due to multiple hypotheses and p-values being between .01 and .05 , the positive associations between RAD symptom load and the categorical measures of depression and self-harm, and between a RAD diagnosis and suicidal thoughts, must be interpreted with caution. However, the statistically convincing associations between a RAD diagnosis and the CBCL withdrawn/ depressed scale, and between RAD symptom load and most CBCL syndrome scales, demonstrate the importance of assessing emotional problems in adolescents with RAD.

\section{DSED}

The prevalence rates of ADHD and CD/ODD in adolescents with DSED resemble findings in preschool and school-aged children with signs of DSED, including home-reared [11] and post-institutionally adopted [44] children. Concordant with findings in preschool, school age and young adulthood $[11,19,45,47]$, we found DSED in adolescence to be associated with ADHD. Although we failed to reveal associations between DSED and categorical emotional disorders, the most frequently co-occurring disorders among adolescents with DSED were depression and anxiety, each present in over half of those with a DSED diagnosis. Emotional problems were more prevalent among adolescents with DSED in this sample than reports of post-institutionalized adopted school children [44], possibly reflecting developmental differences such as increasing emotional problems in adolescence [2] or factors related to the care context [74], as discussed above in relation to RAD. Further, three of the findings - that suicidal thoughts occurred more frequently in adolescents with DSED than in those without, that half of the adolescents with a DSED diagnosis reported previous suicidal attempts, and that adolescents with a DSED diagnosis were more prone to intentionally using substances for mood improvement-underscore the importance of assessing emotional problems, including suicidality and emotion regulation from substance use, in adolescents with DSED. 
Due to multiple hypotheses and p-values being between .01 and .05 , the associations between DSED in adolescence and the categorical measures of ADHD, any comorbid disorder, suicidal thoughts and substance use for mood improvement must be interpreted with caution. Nevertheless, as for RAD, the few and weak associations between a DSED diagnosis and the categorical measures of co-occurring psychopathology may be masked by the high-risk nature of the comparison group with a very high psychiatric morbidity in adolescents without DSED. Even so, all the investigated disorders and psychosocial problems were numerically more prevalent among adolescents with DSED diagnosis than those without. Further, as the dimensional approach to co-occurring psychopathology revealed strong associations between a DSED diagnosis and both emotional and behavioral problems, while the categorical approach did not, it seems plausible that results regarding the latter are subject to type-II error due to the reduced power of the categorical dependent variables.

The positive associations between DSED symptom load and all but two CBCL syndrome scales (withdrawn/ depressed and somatic complaints) cohere with findings in other non-institutionalized adolescents exposed to in-family maltreatment, where DSED symptoms were strongly associated with all CBCL syndrome scales except the withdrawn/ depressed and somatic complaint scales [46]. The overall finding that DSED in adolescence is associated with both emotional and behavioral problems is also in line with some results from studies of younger children $[36,39]$.

\section{Strengths and limitations}

The use of in-depth semi-structured psychiatric interviews in a national and comparatively large sample of high-risk adolescents constitutes a clear strength. Further, the combined use of self- and caregiver reports for other psychopathology and psychosocial problems reduced the risk of common rater bias. However, we acknowledge some limitations. Our assessment of RAD and DSED was limited to caregiver (primary contact) information. Although a caregiver-informed approach to RAD and DSED is common in research [2, $23,24]$, clinical recommendations entail a multi-method approach, including observational assessments [13, 65]. Both a risk of over-identification [78] and under-identification [12] have been demonstrated in caregiver reports of RAD and DSED. However, caregiver assessments of RAD and DSED have also been found to converge with observational measures [13, 19, 22, 43], lending support to our findings. A related limitation for RAD, but not for DSED, is uncertainty as to whether aberrant attachment behavior registered by the primary contacts in the RYC was representative of the adolescents' attachment behavior toward previous caregivers. Previous findings of the trans-relational nature of RAD [43] support the suitability of our approach. Further, for the DSM-5 RAD A criterion, we only had available information on the adolescents' comfort-seeking behavior and no information on their response to comfort. This may have influenced our results by deflating the number of RAD symptoms in the measure of symptom load and inflating the number of participants with a RAD diagnosis. Additionally, we were only able to substantiate, not document with certainty, the DSM-5 criteria of early exposure to extremely insufficient care and the presence of RAD symptoms prior to age 5, possibly inflating our diagnostics of RAD and DSED. However, careful measures were taken to minimize the risk of over-diagnosing RAD and DSED, and the prevalence rates of RAD and DSED herein are concordant with the findings in foster children in Norway [33]. Thus, we consider the risk of overdiagnosis to be limited.

Due to developmental changes and heterotypic continuity of disorders and symptoms, the rates of co-occurrence and the degree of associations reported herein cannot necessarily be ascribed to other age groups. Further, the prevalence rates of comorbid disorders and psychosocial problems are likely to be context dependent, and may therefore differ for adolescents in non-RYC settings-such as adolescents with early placement in well-functioning and lasting foster/adoptive homes or adolescents placed in larger-sized or less developmentally supportive RYCs - and those in other countries. Because adolescent behavioral problems and drug use are more frequently cited reasons for placement in RYC than in foster care [54], we would expect foster-placed adolescents with RAD and DSED to have somewhat lower co-occurrence of behavioral problems and drug use than adolescents with RAD and DSED in RYC.

\section{Clinical implications}

As this is the first in-depth and multi-approach investigation of co-occurring psychopathology and psychosocial problems among adolescents with RAD and DSED, the clinical value is presumably high. Because other psychiatric disorders and psychosocial problems frequently co-occur with RAD and DSED in adolescence, all adolescents with RAD or DSED symptoms or diagnoses should receive comprehensive psychiatric assessment in accordance with the practice parameter [65]. Clinicians should, in their assessments of adolescents with RAD or DSED, systematically consider possible comorbid emotional and behavioral disorders as well as related psychosocial problems, including suicidality, bullying experience, juridical offenses, sexual activity and substance use. Because disclosing such problems may provoke feelings of shame and taboo, adolescents may not spontaneously present them in conversation or general assessment. However, becoming aware of these additional psychosocial problems might impact the overall understanding of the adolescent's daily 
challenges and might be crucial in terms of offering adequate treatment and support. Our findings underline the importance of permitting diagnostic comorbidity so that all aspects of an individual's mental health problems may be incorporated into a comprehensive understanding of what support and treatment are needed. This is contrary to the general medical principle of combining symptoms to a minimum number of diagnoses. We maintain, however, that the discriminant validity demonstrated for RAD and DSED in previous studies, combined with this and other studies demonstrating the clinically important ramifications of early maltreatment and neglect, imply that clinicians should seek to grasp the full complexity rather than simplify their understanding in the assessment and treatment of these high-risk individuals.

\section{Conclusion}

Most adolescents with RAD or DSED disorders or symptoms have additional psychiatric disorders and psychosocial problems of an emotional and/or behavioral nature, warranting easy access to high-quality psychiatric health care, including a comprehensive psychiatric assessment where comorbidity is acknowledged, and treatment plans are adjusted accordingly.

Acknowledgements We thank all the adolescents and institutional staff who participated and the research assistants who collected the data. The data collection was funded by the Norwegian Directorate for Children, Youth and Family Affairs, the Norwegian Directorate of Health and the Regional Centre for Child and Youth Mental Health and Child Welfare, Faculty of Medicine, the Norwegian University of Science and Technology (NTNU).

Funding Open Access funding provided by NTNU Norwegian University of Science and Technology (incl St. Olavs Hospital - Trondheim University Hospital). The study was funded by The Department of Research and Development (AFFU), Division of Mental Health Care, St. Olavs Hospital, and the Joint Research Committee between St. Olavs Hospital and the Faculty of Medicine and Health Sciences at NTNU.

Availability of data and material Access to data by project manager Nanna S. Kayed.

\section{Compliance with ethical standards}

Conflict of interest The authors declare that they have no conflict of interest.

Ethics The Norwegian Regional Committee for Medical and Health Research Ethics (REK) approved the study (reference number: 2015/1474/REC central Norway). Written informed consent was obtained from all participants, and the study was congruent with current ethical standards.

Open Access This article is licensed under a Creative Commons Attribution 4.0 International License, which permits use, sharing, adaptation, distribution and reproduction in any medium or format, as long as you give appropriate credit to the original author(s) and the source, provide a link to the Creative Commons licence, and indicate if changes were made. The images or other third party material in this article are included in the article's Creative Commons licence, unless indicated otherwise in a credit line to the material. If material is not included in the article's Creative Commons licence and your intended use is not permitted by statutory regulation or exceeds the permitted use, you will need to obtain permission directly from the copyright holder. To view a copy of this licence, visit http://creativecommons.org/licenses/by/4.0/.

\section{References}

1. Hughes K, Bellis MA, Hardcastle KA, Sethi D, Butchart A, Mikton C, Jones L, Dunne MP (2017) The effect of multiple adverse childhood experiences on health: a systematic review and meta-analysis. Lancet Public Health 2(8):e356-e366. https ://doi.org/10.1016/S2468-2667(17)30118-4

2. Sonuga-Barke EJS, Kennedy M, Kumsta R, Knights N, Golm D, Rutter M, Maughan B, Schlotz W, Kreppner J (2017) Childto-adult neurodevelopmental and mental health trajectories after early life deprivation: the young adult follow-up of the longitudinal English and Romanian Adoptees study. Lancet 389(10078):1539-1548. https://doi.org/10.1016/S0140 -6736(17)30045-4

3. Norman RE, Byambaa M, De R, Butchart A, Scott J, Vos T, Tomlinson M (2012) The long-term health consequences of child physical abuse, emotional abuse, and neglect: a systematic review and meta-analysis (consequences of child nonsexual maltreatment). PloS Med 9(11):e1001349. https://doi.org/10.1371/journ al.pmed.1001349

4. American Psychiatric Association (2013) Diagnostic and statistical manual of mental disorders : DSM-5, 5th edn. American Psychiatric Association, Washington, D.C.

5. John SG, Brandt TW, Secrist ME, Mesman GR, Sigel BA, Kramer TL (2019) Empirically-guided assessment of complex trauma for children in foster care: a focus on appropriate diagnosis of attachment concerns. Psychol Serv 16(1):120-133. https://doi. org/10.1037/ser0000263

6. Chaffin M, Saunders RHBE, Nichols T, Barnett D, Zeanah C, Berliner L, Egeland B, Newman E, Lyon T, Letourneau E, MillerPerrin C (2006) Report of the APSAC task force on attachment therapy, reactive attachment disorder, and attachment problems. Child Maltreatment 11(1):76-89. https://doi.org/10.1177/10775 59505283699

7. Woolgar M, Baldock E (2015) Attachment disorders versus more common problems in looked after and adopted children: comparing community and expert assessments. Child Adolesc Mental Health 20(1):34-40. https://doi.org/10.1111/camh.12052

8. Woolgar M, Scott S (2014) The negative consequences of overdiagnosing attachment disorders in adopted children: the importance of comprehensive formulations. Clin Child Psychol Psychiatry 19(3):355-366. https://doi.org/10.1177/1359104513478545

9. Allen B, Schuengel C (2020) Attachment disorders diagnosed by community practitioners: a replication and extension. Child Adolesc Mental Health 25(1):4-10. https://doi.org/10.1111/ camh. 12338

10. Zimmermann P, Soares I (2019) Recent contributions for understanding inhibited reactive attachment disorder. Attach Hum Dev 21(2):87-94. https://doi.org/10.1080/14616734.2018.1499207

11. Scheper FY, Groot CRM, de Vries ALC, Doreleijers TAH, Jansen LMC, Schuengel C (2018) Course of disinhibited social engagement behavior in clinically referred home-reared preschool children. J Child Psychol Psychiatry 60(5):555-565. https://doi. org/10.1111/jcpp.12994 
12. Bruce M, Young D, Turnbull S, Rooksby M, Chadwick G, Oates C, Nelson R, Young-Southward G, Haig C, Minnis H (2019) Reactive attachment disorder in maltreated young children in foster care. Attach Hum Dev 21(2):152-169. https://doi. org/10.1080/14616734.2018.1499211

13. Atkinson L (2019) Reactive attachment disorder and attachment theory from infancy to adolescence: review, integration, and expansion. Attach Hum Dev 21(2):205-217. https://doi. org/10.1080/14616734.2018.1499214

14. Costello EJ, Mustillo S, Erkanli A, Keeler G, Angold A (2003) Prevalence and development of psychiatric disorders in childhood and adolescence. Arch Gen Psychiatry 60(8):837-844. https://doi. org/10.1001/archpsyc.60.8.837

15. de Girolamo G, Dagani J, Purcell R, Cocchi A, McGorry PD (2012) Age of onset of mental disorders and use of mental health services: needs, opportunities and obstacles. Epidemiol Psychiatr Sci 21(1):47-57. https://doi.org/10.1017/s2045796011000746

16. Lehmann S, Breivik K, Heiervang ER, Havik T, Havik OE (2016) Reactive attachment disorder and disinhibited social engagement disorder in school-aged foster children: a confirmatory approach to dimensional measures. J Abnorm Child Psychol 44(3):445-457. https://doi.org/10.1007/s10802-015-0045-4

17. Davidson C, Ohare A, Mactaggart F, Green J, Young D, Gillberg C, Minnis H (2015) Social relationship difficulties in autism and reactive attachment disorder: improving diagnostic validity through structured assessment. Res Dev Disabil 40:63-72. https ://doi.org/10.1016/j.ridd.2015.01.007

18. Follan M, Anderson S, Huline-Dickens S, Lidstone E, Young D, Brown G, Minnis H (2011) Discrimination between attention deficit hyperactivity disorder and reactive attachment disorder in school aged children. Res Dev Disabil Multidiscip J 32(2):520526. https://doi.org/10.1016/j.ridd.2010.12.031

19. Gleason MM, Fox NA, Drury S, Smyke A, Egger HL, Nelson CA, Gregas MC, Zeanah CH (2011) Validity of evidence-derived criteria for reactive attachment disorder: indiscriminately social/ disinhibited and emotionally withdrawn/inhibited types. J Am Acad Child Adolesc Psychiatry 50(3):216-231. https://doi. org/10.1016/j.jaac.2010.12.012

20. Giltaij HP, Sterkenburg PS, Schuengel C (2015) Psychiatric diagnostic screening of social maladaptive behaviour in children with mild intellectual disability: differentiating disordered attachment and pervasive developmental disorder behaviour. J Intellect Disabil Res 59(2):138-149. https://doi.org/10.1111/jir.12079

21. Seim AR, Jozefiak T, Wichstrøm L, Kayed NS (2019) Validity of reactive attachment disorder and disinhibited social engagement disorder in adolescence. Eur Child Adolesc Psychiatry. https://doi. org/10.1007/s00787-019-01456-9

22. Zeanah CH, Gleason MM (2015) Annual research review: attachment disorders in early childhood-clinical presentation, causes, correlates, and treatment. J Child Psychol Psychiatry 56(3):207222. https://doi.org/10.1111/jcpp.12347

23. Humphreys KL, Nelson CA, Fox NA, Zeanah CH (2017) Signs of reactive attachment disorder and disinhibited social engagement disorder at age 12 years: effects of institutional care history and high-quality foster care. Dev Psychopathol 29(2):675-684. https ://doi.org/10.1017/S0954579417000256

24. Lehmann S, Monette S, Egger H, Breivik K, Young D, Davidson C, Minnis H (2018) Development and examination of the reactive attachment disorder and disinhibited social engagement disorder assessment interview. Assessment. https://doi.org/10.1177/10731 91118797422

25. Guyon-Harris KL, Humphreys KL, Fox NA, Nelson CA, Zeanah $\mathrm{CH}$ (2018) Course of disinhibited social engagement disorder from early childhood to early adolescence. J Am Acad Child Adolesc Psychiatry 57(5):329-335. https://doi.org/10.1016/j. jaac.2018.02.009
26. Guyon-Harris KL, Humphreys KL, Degnan K, Fox NA, Nelson CA, Zeanah CH (2019) A prospective longitudinal study of Reactive Attachment Disorder following early institutional care: considering variable- and person-centered approaches. Attach Hum Dev 21(2):95-110. https://doi.org/10.1080/14616734.2018.14992 08

27. American Psychiatric Association Task Force on DSM-IV (2000) Diagnostic and statistical manual of mental disorders: DSM-IVTR, 4th edn. American Psychiatric Association, Washington, DC

28. Kocovska E, Puckering C, Follan M, Smillie M, Gorski C, Barnes J, Wilson P, Young D, Lidstone E, Pritchett R, Hockaday H, Minnis H (2012) Neurodevelopmental problems in maltreated children referred with indiscriminate friendliness. Res Dev Disabil 33(5):1560-1565. https://doi.org/10.1016/j.ridd.2012.02.016

29. Minnis H, Macmillan S, Pritchett R, Young D, Wallace B, Butcher J, Sim F, Baynham K, Davidson C, Gillberg C, Minnis H (2013) Prevalence of reactive attachment disorder in a deprived population. Br J Psychiatry 202:342-346. https://doi.org/10.1192/bjp. bp.112.114074

30. Pritchett R, Pritchett J, Marshall E, Davidson C, Minnis H (2013) Reactive attachment disorder in the general population: a hidden ESSENCE disorder. Sci World J. https://doi. org/10.1155/2013/818157

31. Mayes SD, Calhoun SL, Waschbusch DA, Breaux RP, Baweja R (2017) Reactive attachment/disinhibited social engagement disorders: callous-unemotional traits and comorbid disorders. Res Dev Disabil 63:28-37. https://doi.org/10.1016/j.ridd.2017.02.012

32. Minnis H, Green J, O'Connor TG, Liew A, Glaser D, Taylor E, Follan M, Young D, Barnes J, Gillberg C, Pelosi A, Arthur J, Burston A, Connolly B, Sadiq FA (2009) An exploratory study of the association between reactive attachment disorder and attachment narratives in early school-age children. J Child Psychol Psychiatry 50(8):931-942. https://doi.org/10.111 1/j.1469-7610.2009.02075.x

33. Lehmann S, Havik OE, Havik T, Heiervang ER (2013) Mental disorders in foster children: a study of prevalence, comorbidity and risk factors. Child Adolesc Psychiatry Ment Health 7(1):39. https://doi.org/10.1186/1753-2000-7-39

34. Millward R, Kennedy E, Towlson K, Minnis H (2006) Reactive attachment disorder in looked-after children. Emot Behav Difficult 11(4):273-279. https://doi.org/10.1080/13632750601022212

35. Moran K, McDonald J, Jackson A, Turnbull S, Minnis H (2017) A study of Attachment Disorders in young offenders attending specialist services. Child Abuse Negl 65:77-87. https://doi. org/10.1016/j.chiabu.2017.01.009

36. Jonkman CS, Oosterman M, Schuengel C, Bolle EA, Boer F, Lindauer RJL (2014) Disturbances in attachment: inhibited and disinhibited symptoms in foster children. Child Adolesc Psychiatry Ment Health. https://doi.org/10.1186/1753-2000-8-21

37. Schroder M, Ludtke J, Fux E, Izat Y, Bolten M, Gloger-Tippelt G, Suess GJ, Schmid M (2019) Attachment disorder and attachment theory-two sides of one medal or two different coins? Compr Psychiatry. https://doi.org/10.1016/j.comppsych.2019.152139

38. Gleason MM, Zamfirescu A, Egger HL, Nelson CA, Fox NA, Zeanah CHJEC, Psychiatry A (2011) Epidemiology of psychiatric disorders in very young children in a Romanian pediatric setting. Eur Child Adolesc Psychiatry 20(10):527. https://doi.org/10.1007/ s00787-011-0214-0

39. McGoron L, Gleason MM, Smyke AT, Drury SS, Nelson CA 3rd, Gregas MC, Fox NA, Zeanah CH (2012) Recovering from early deprivation: attachment mediates effects of caregiving on psychopathology. J Am Acad Child Adolesc Psychiatry 51(7):683-693. https://doi.org/10.1016/j.jaac.2012.05.004

40. Spangler G, Bovenschen I, Jorjadze N, Zimmermann J, Werner A, Riedel N, Gabler S, Kliewer-Neumann JD, Nowacki K (2019) Inhibited symptoms of attachment disorder in children from 
institutional and foster care samples. Attach Hum Dev 21(2):132151. https://doi.org/10.1080/14616734.2018.1499210

41. Vervoort E, De Schipper J, Bosmans G, Verschueren K (2013) Screening symptoms of reactive attachment disorder: evidence for measurement invariance and convergent validity. Int J Methods Psychiatr Res 22(3):256-265. https://doi.org/10.1002/mpr.1395

42. Giltaij HP, Sterkenburg PS, Schuengel C (2016) Adaptive behaviour, comorbid psychiatric symptoms, and attachment disorders. Adv Ment Health Intellect Disabil 10(1):82-91. https://doi. org/10.1108/AMHID-07-2015-0035

43. Zimmermann P, Iwanski A (2019) Attachment Disorder behavior in early and middle childhood: associations with children's selfconcept and observed signs of negative internal working models. Attach Hum Dev 21(2):170-189. https://doi.org/10.1080/14616 734.2018.1499212

44. Rutter M, Colvert E, Kreppner J, Beckett C, Castle J, Groothues C, Hawkins A, O'Connor TG, Stevens SE, Sonuga-barke EJS (2007) Early adolescent outcomes for institutionally-deprived and non-deprived adoptees. I: Disinhibited attachment. J Child Psychol Psychiatry 48(1):17-30. https://doi.org/10.111 1/j.1469-7610.2006.01688.x

45. Kay C, Green J, Sharma K (2016) Disinhibited attachment disorder in UK adopted children during middle childhood: prevalence, validity and possible developmental origin. J Abnorm Child Psychol 44(7):1375-1386. https://doi.org/10.1007/s1080 2-016-0131-2

46. Kay C, Green J (2013) Reactive attachment disorder following early maltreatment: systematic evidence beyond the institution. J Abnorm Child Psychol 41(4):571-581. https://doi.org/10.1007/ s10802-012-9705-9

47. Kennedy M, Kreppner J, Knights N, Kumsta R, Maughan B, Golm D, Hill J, Rutter M, Schlotz W, Sonuga-Barke E (2017) Adult disinhibited social engagement in adoptees exposed to extreme institutional deprivation: examination of its clinical status and functional impact. Br J Psychiatry 211(5):289. https://doi.org/10.1192/ bjp.bp.117.200618

48. Kreppner J, Kumsta R, Rutter M, Beckett C, Castle J, Stevens S, Sonuga-Barke EJ (2010) Developmental course of deprivationspecific psychological patterns: early manifestations, persistence to age 15, and clinical features. Monogr Soc Res Child Dev 75(1):79-101. https://doi.org/10.1111/j.1540-5834.2010.00551.x

49. Stoltenborgh M, Bakermans-Kranenburg MJ, Alink LRA, Ijzendoorn MH (2015) The prevalence of child maltreatment across the globe: review of a series of meta-analyses. Child Abuse Rev 24(1):37-50. https://doi.org/10.1002/car.2353

50. Stafford B, Zeanah CH, Scheeringa M, Guedeney A, Maestro S (2003) Exploring psychopathology in early childhood: pTSD and attachment disorders in DC: 0-3 and DSM-IV. Infant Mental Health J 24(4):398-409. https://doi.org/10.1002/imhj.10064

51. Jozefiak T, Kayed N, Rimehaug T, Wormdal A, Brubakk A, Wichstrøm L (2016) Prevalence and comorbidity of mental disorders among adolescents living in residential youth care. Eur Child Adolesc Psychiatry 25(1):33-47. https://doi.org/10.1007/s0078 7-015-0700-x

52. Greger HK, Myhre AK, Lydersen S, Jozefiak T (2015) Previous maltreatment and present mental health in a high-risk adolescent population. Child Abuse Negl 45:122-134. https://doi. org/10.1016/j.chiabu.2015.05.003

53. Bufdir.no (2018) Barnevernsstatistikk (Statistics of the Child Proctection Service) (2018). Barne- ungdoms- og familiedirektoratet (The Norwegian Directorate for Children, Youth and Family Affairs). https://www.bufdir.no/Statistikk_og_analyse/Barne vern/. Accessed 11 Mar 2020

54. Backe-Hansen E, Bakketeig E, Gautun H, Grønningsæter AB (2011) Institusjonsplassering - siste utvei. Betydningen av barnevernsreformen fra 2004 for institusjonstilbudet (Placement in institutions - the last opportunity. The importance of the child welfare reform in 2004 for placement policy in institutions). NOVA, vol 21/2011. Norsk institutt for forskning om oppvekst, velferd og aldring, Oslo

55. Lovdata.no (2018) Lov om barneverntjenester (Act relating to child protection services). Barne- og familiedepartementet (The Norwegian Ministry of Children and Families). https://lovdata.no/ dokument/NL/lov/1992-07-17-100/KAPITTEL_4\#KAPITTEL_4. Accessed 11 Mar 2020

56. Lovdata.no (2008) Forskrift om krav til kvalitet og internkontroll i barneverninstitusjoner (Regulation concerning requirements to quality and internal control in child welfare institutions). Barneog familiedepartementet (The Norwegian Ministry of Children and Families). https://lovdata.no/dokument/SF/forskrift/2008-0610-580. Accessed 11 Mar 2020

57. Kayed NS, Jozefiak T, Rimehaug T, Tjelflaat T, Brubakk A-M, Wichstrøm L (2015) Resultater fra forskningsprosjektet Psykisk helse hos barn og unge i barneverninstitusjoner. NTNU Regionalt kunnskapssenter for barn og unge-Psykisk helse og barnevern, https://www.ntnu.no/documents/10293/1263899358/Barnevernr apport_RKBU.pdf. Accessed 11 Mar 2020

58. Angold A, Costello EJ (2000) The child and adolescent psychiatric assessment (CAPA). J Am Acad Child Adolesc Psychiatry 39(1):39-48. https://doi.org/10.1097/00004583-20000 1000-00015

59. Owens J, Goldfine M, Evangelista N, Hoza B, Kaiser N (2007) A critical review of self-perceptions and the positive illusory bias in children with ADHD. Clin Child Fam Psychol Rev 10(4):335351. https://doi.org/10.1007/s10567-007-0027-3

60. Fonagy P (2002) Affect regulation, mentalization, and the development of the self. Other Press, New York

61. Egger HL, Erkanli A, Keeler G, Potts E, Walter BK, Angold A (2006) Test-retest reliability of the preschool age psychiatric assessment (PAPA). J Am Acad Child Adolesc Psychiatry 45(5):538-549. https://doi.org/10.1097/01.chi.0000205705.71194 .b8

62. Achenbach TM, Rescorla L (2001) Manual for the ASEBA schoolage forms \& profiles: an integrated system of multi-informant assessment. ASEBA, Burlington

63. van Buuren S (2018) Flexible imputation of missing data. CRC interdisciplinary statistic series, 2nd edn. CRC Press, Boca Raton

64. Rodwell L, Lee KJ, Romaniuk H, Carlin JB (2014) Comparison of methods for imputing limited-range variables: a simulation study. BMC Med Res Methodol 14(1):57. https://doi. org/10.1186/1471-2288-14-57

65. Zeanah CH, Chesher T, Boris NW (2016) Practice parameter for the assessment and treatment of children and adolescents with reactive attachment disorder and disinhibited social engagement disorder. J Am Acad Child Adolesc Psychiatry 55(11):990. https ://doi.org/10.1016/j.jaac.2016.08.004

66. Polanczyk GV, Salum GA, Sugaya LS, Caye A, Rohde LA (2015) Annual research review: a meta-analysis of the worldwide prevalence of mental disorders in children and adolescents. J Child Psychol Psychiatry 56(3):345-365. https://doi.org/10.1111/ jcpp.12381

67. Reneflot A, Aarø LE, Aase H, Reichborn-Kjennerud T, Tambs K, Øverland S (2018) Psykisk helse i Norge (Mental health in Norway). Norwegian Institute of Public Health, https://www.fhi. no/globalassets/dokumenterfiler/rapporter/2018/psykisk_helse _i_norge2018.pdf. Accessed 11 Mar 2020

68. Rescorla L, Ivanova MY, Achenbach TM, Begovac I, Chahed M, Drugli MB, Emerich DR, Fung DSS, Haider M, Hansson K, Hewitt N, Jaimes S, Larsson B, Maggiolini A, Marković J, Mitrović D, Moreira P, Oliveira JT, Olsson M, Ooi YP, Petot D, Pisa C, Pomalima R, da Rocha MM, Rudan V, Sekulić S, Shahini M, de Mattos Silvares EF, Szirovicza L, Valverde J, Vera LA, 
Villa MC, Viola L, Woo BSC, Zhang EY (2012) International epidemiology of child and adolescent psychopathology II: integration and applications of dimensional findings from 44 societies. J Am Acad Child Adolesc Psychiatry 51(12):1273-1283.e1278. https://doi.org/10.1016/j.jaac.2012.09.012

69. Nøvik TS (1999) Validity and use of the child behavior checklist in Norwegian children and adolescents : an epidemiological and clinical study. Department of Psychiatry, University of Oslo, Centre for Child and Adolescent Psychiatry, Oslo

70. NOVA (2015) Ungdata. Nasjonale resultater 2014. Nova Rapport 7/15. (Youth Data. National Results 2014). Oslo: Norsk institutt for for forskning om oppvekst, velferd og aldring (NOVA) (Norwegian Social Research)

71. Cohen P, Brown J, Smailes E (2001) Child abuse and neglect and the development of mental disorders in the general population. Dev Psychopathol 13(4):981-999

72. Humphreys KL, Gleason MM, Drury SS, Miron D, Nelson CA, Fox NA, Zeanah CH (2015) Effects of institutional rearing and foster care on psychopathology at age 12 years in Romania: follow-up of an open, randomised controlled trial. Lancet Psychiatry 2(7):625-634. https://doi.org/10.1016/S2215-0366(15)00095-4

73. Zeanah CH, Egger HL, Smyke AT, Nelson CA, Fox NA, Marshall PJ, Guthrie D (2009) Institutional rearing and psychiatric disorders in Romanian preschool children. Am J Psychiatry 166(7):777-785. https://doi.org/10.1176/appi.ajp.2009.08091438
74. Jones R, Everson-Hock E, Papaioannou D, Guillaume L, Goyder E, Chilcott J, Cooke J, Payne N, Duenas A, Sheppard L, Swann C (2011) Factors associated with outcomes for looked-after children and young people: a correlates review of the literature. Child Care Health Dev 37(5):613-622. https://doi.org/10.111 1/j.1365-2214.2011.01226.x

75. Corval R, Belsky J, Baptista J, Mesquita A, Soares I (2019) Development and validation of an observational measure of symptoms of reactive attachment disorder. Attach Hum Dev 21(2):111-131. https://doi.org/10.1080/14616734.2018.1499209

76. Allen B (2018) Misperceptions of reactive attachment disorder persist: poor methods and unsupported conclusions. Res Dev Disabil 77:24-29. https://doi.org/10.1016/j.ridd.2018.03.012

77. Lehmann S, Breivik K, Monette S, Minnis H (2020) Potentially traumatic events in foster youth, and association with DSM-5 trauma- and stressor related symptoms. Child Abuse Negl. https ://doi.org/10.1016/j.chiabu.2020.104374

78. Giltaij HP, Sterkenburg PS, Schuengel C (2017) Convergence between observations and interviews in clinical diagnosis of reactive attachment disorder and disinhibited social engagement disorder. Clin Child Psychol Psychiatry 22(4):603-619. https:// doi.org/10.1177/1359104517709049 